\section{(6) OPEN ACCESS}

\begin{abstract}
Handling editor Tore K Kvien
- Additional material is published online only. To view please visit the journal online (http://dx.doi.org/10.1136/ annrheumdis-2017-211682).

For numbered affiliations see end of article.

Correspondence to

Dr Dinesh Khanna, Division of Rheumatology, Department of Internal Medicine, University of Michigan Scleroderma Program, Ann Arbor MI 48109, USA; khannad@med.umich.edu
\end{abstract}

Received 21 April 2017 Revised 15 September 2017 Accepted 19 September 2017 Published Online First 26 October 2017

\title{
Safety and efficacy of subcutaneous tocilizumab in systemic sclerosis: results from the open-label period of a phase II randomised controlled trial (faSscinate)
}

\author{
Dinesh Khanna, ${ }_{1}^{1}$ Christopher P Denton, ${ }^{2}$ Celia J F Lin, ${ }_{1}^{3}$ Jacob M van Laar, ${ }^{4}$ \\ Tracy M Frech, ${ }^{5}$ Marina E Anderson, ${ }^{6}$ Murray Baron, ${ }^{7}$ Lorinda Chung, ${ }^{8}$ \\ Gerhard Fierlbeck, ${ }^{9}$ Santhanam Lakshminarayanan, ${ }^{10}$ Yannick Allanore, ${ }^{11}$ \\ Janet E Pope, ${ }^{12}$ Gabriela Riemekasten, ${ }^{13}$ Virginia Steen, ${ }^{14}$ Ulf Müller-Ladner, ${ }^{15}$ \\ Helen Spotswood, ${ }^{16}$ Laura Burke, ${ }^{16}$ Jeffrey Siegel, ${ }^{3}$ Angelika Jahreis, ${ }^{3}$ Daniel E Furst ${ }^{17}$
}

\section{ABSTRACT}

Objectives Assess the efficacy and safety of tocilizumab in patients with systemic sclerosis (SSC) in a phase II study.

Methods Patients with SSc were treated for 48 weeks in an open-label extension phase of the fasscinate study with weekly $162 \mathrm{mg}$ subcutaneous tocilizumab. Exploratory end points included modified Rodnan Skin Score (mRSS) and per cent predicted forced vital capacity (\%pFVC) through week 96.

Results Overall, 24/44 (55\%) placebo-tocilizumab and $27 / 43(63 \%)$ continuous-tocilizumab patients completed week 96. Observed mean (SD (95\% CI)) change from baseline in mRSS was -3.1 (6.3 (-5.4 to -0.9$))$ for placebo and $-5.6(9.1(-8.9$ to -2.4$))$ for tocilizumab at week 48 and $-9.4(5.6(-8.9$ to -2.4$))$ for placebo-tocilizumab and -9.1 (8.7 (-12.5 to -5.6$))$ for continuous-tocilizumab at week 96 . Of patients who completed week 96 , any decline in \%pFVC was observed for $10 / 24(42 \%(95 \% \mathrm{Cl} 22 \%$ to $63 \%))$ placebotocilizumab and $12 / 26$ (46\% (95\% Cl $27 \%$ to $67 \%)$ ) continuous-tocilizumab patients in the open-label period; no patients had $>10 \%$ absolute decline in $\% p F V C$. Serious infection rates/100 patient-years $(95 \% \mathrm{Cl})$ were 10.9 (3.0 to 27.9) with placebo and 34.8 (18.0 to 60.8) with tocilizumab during the double-blind period by week 48 and 19.6 (7.2 to 42.7) with placebo-tocilizumab and 0.0 (0.0 to 12.2 ) with continuous-tocilizumab during the open-label period.

Conclusions Skin score improvement and FVC stabilisation in the double-blind period were observed in placebo-treated patients who transitioned to tocilizumab and were maintained in the open-label period. Safety data indicated increased serious infections in patients with SSc but no new safety signals with tocilizumab. Trial registration number NCT01532869; Results.

\section{INTRODUCTION}

Systemic sclerosis (SSc) is a rare, debilitating autoimmune disorder of the connective tissue and vasculature that is characterised by inflammation, fibrosis and microvascular injury of multiple organs. ${ }^{1-3}$ Patients with SSc experience high morbidity and mortality rates, ${ }^{2}$ particularly those who have pulmonary, cardiac or renal organ involvement. ${ }^{4}$ Indeed, lung disease is the primary cause of scleroderma-related deaths. ${ }^{15}$ Few treatment options are available for patients with SSc, and there is an unmet need for disease-modifying therapy. ${ }^{6}$

Interleukin 6 (IL-6) appears to play a role in SSc pathogenesis. ${ }^{78}$ Patients with SSc have increased IL-6 expression in endothelial cells and skin fibroblasts. ${ }^{9}$ Serum IL-6 levels are elevated in patients with SSc, ${ }^{10} 11$ particularly those with early diffuse cutaneous skin involvement. ${ }^{12}{ }^{13}$ Furthermore, some studies have suggested a role for IL-6 as a marker for disease progression and clinical outcome in patients with $\mathrm{SSc}^{11} \mathrm{C}$ reactive protein (CRP) is correlated with IL-6, and CRP levels are elevated in patients with active SSc, especially those with early diffuse cutaneous SSc. ${ }^{14}$

Tocilizumab is a monoclonal anti-IL-6 receptor- $\alpha$ antibody for the treatment of patients with rheumatoid arthritis, systemic juvenile idiopathic arthritis, polyarticular juvenile idiopathic arthritis and giant cell arteritis. ${ }^{15}$ Initial investigations of tocilizumab in patients with SSc demonstrated improvements in skin sclerosis and SSc-associated polyarthritis. ${ }^{16} 17$ The faSScinate clinical trial was the first doubleblind, randomised controlled trial investigating the efficacy and safety of subcutaneous tocilizumab in patients with SSc. Results from the 48-week doubleblind period of faSScinate, including the primary end point, were published previously and demonstrated that treatment with tocilizumab resulted in a clinically meaningful but not statistically significant decline in modified Rodnan Skin Score (mRSS) compared with placebo through week 48 for patients receiving tocilizumab. ${ }^{18}$ Exploratory efficacy results and safety through week 96 of the faSScinate trial, including the 48 -week open-label period, are now reported.

\section{METHODS}

\section{Study design}

faSScinate was a multicentre, randomised, doubleblind, placebo-controlled, two-arm, parallel-group, phase II clinical trial conducted at 35 hospitals across Canada, France, Germany, the UK and USA. The study design and patient enrolment criteria have been published. ${ }^{18}$ Briefly, the 96 -week trial consisted of a 48 -week double-blind period 
followed by a 48 -week open-label period. Patients were randomly assigned $(1: 1)$ to receive weekly subcutaneous injections of tocilizumab $162 \mathrm{mg}$ or placebo during the 48 -week double-blind period (tocilizumab group or placebo group, respectively) with the option for escape therapy with methotrexate, hydroxychloroquine or mycophenolate mofetil (MMF) after 24 weeks if they had worsening SSc. Randomisation was stratified according to joint involvement at baseline $(<4$ or $\geq 4$ joints on the 28 tender joint count). At week 48, all patients in the tocilizumab and placebo groups transitioned to open-label weekly injections of tocilizumab $162 \mathrm{mg}$ for another 48 weeks (continuous-tocilizumab and placebo-tocilizumab groups, respectively).

\section{Patients}

Eligible patients were 18 years of age or older; received a diagnosis of SSc according to the 1980 American College of Rheumatology Criteria, ${ }^{19}$ with less than 5 years since their first non-Raynaud's sign or symptom; had an mRSS score of 15 to 40 with clinical skin involvement proximal to the elbows, knees or both, with or without facial involvement; and had active disease. Active disease was defined as at least one of the following features at screening: increase $\geq 3$ in mRSS units compared with the last visit within the previous 1 month to 6 months or new-onset SSc within 1 year before screening, involvement of one new body area with $\geq 2 \mathrm{mRSS}$ units or two new body areas with $\geq 1 \mathrm{mRSS}$ unit, documentation of worsening skin thickening (patients with new-onset SSc only), or $\geq 1$ tendon friction rub plus CRP level $\geq 10 \mathrm{mg} / \mathrm{L}$, erythrocyte sedimentation rate $\geq 28 \mathrm{~mm} /$ hour or platelet count $\geq 330 \times 10^{3} / \mu \mathrm{L}$. All patients provided written informed consent.

\section{Assessments}

Exploratory efficacy end points included mean change from baseline to week 96 in mRSS; proportions of patients with improvements in mRSS of $\geq 20 \%, \geq 40 \%$ and $\geq 60 \%$; proportions of patients achieving minimal clinically important difference (MCID) in mRSS (change from baseline of $\geq 4.7)^{20}$; per cent predicted forced vital capacity (\%pFVC); per cent predicted diffusing capacity for carbon monoxide corrected for haemoglobin (\%pDLCO (Hb corr)) and Clinician Global Visual Analogue Scale (VAS). Patient-reported outcomes included Health Assessment Questionnaire-Disability Index (HAQ-DI), Patient Global VAS, Functional Assessment of Chronic Illness Therapy (FACIT)-Fatigue Score and Pruritus 5-D Itch Scale. Safety was reported as rates of adverse events (AEs) and serious AEs (SAEs) per 100 patient-years (PY) with 95\% CIs.

\section{Statistical analysis}

Although a mixed-model, repeated-measures analysis was performed on the placebo-controlled period at weeks 24 and 48 , observed data were analysed for the week 96 period because all end points during the open-label period were exploratory. Exploratory efficacy end points in the open-label period were assessed in the modified intent-to-treat population (all randomly assigned patients who received any study drug). Safety was

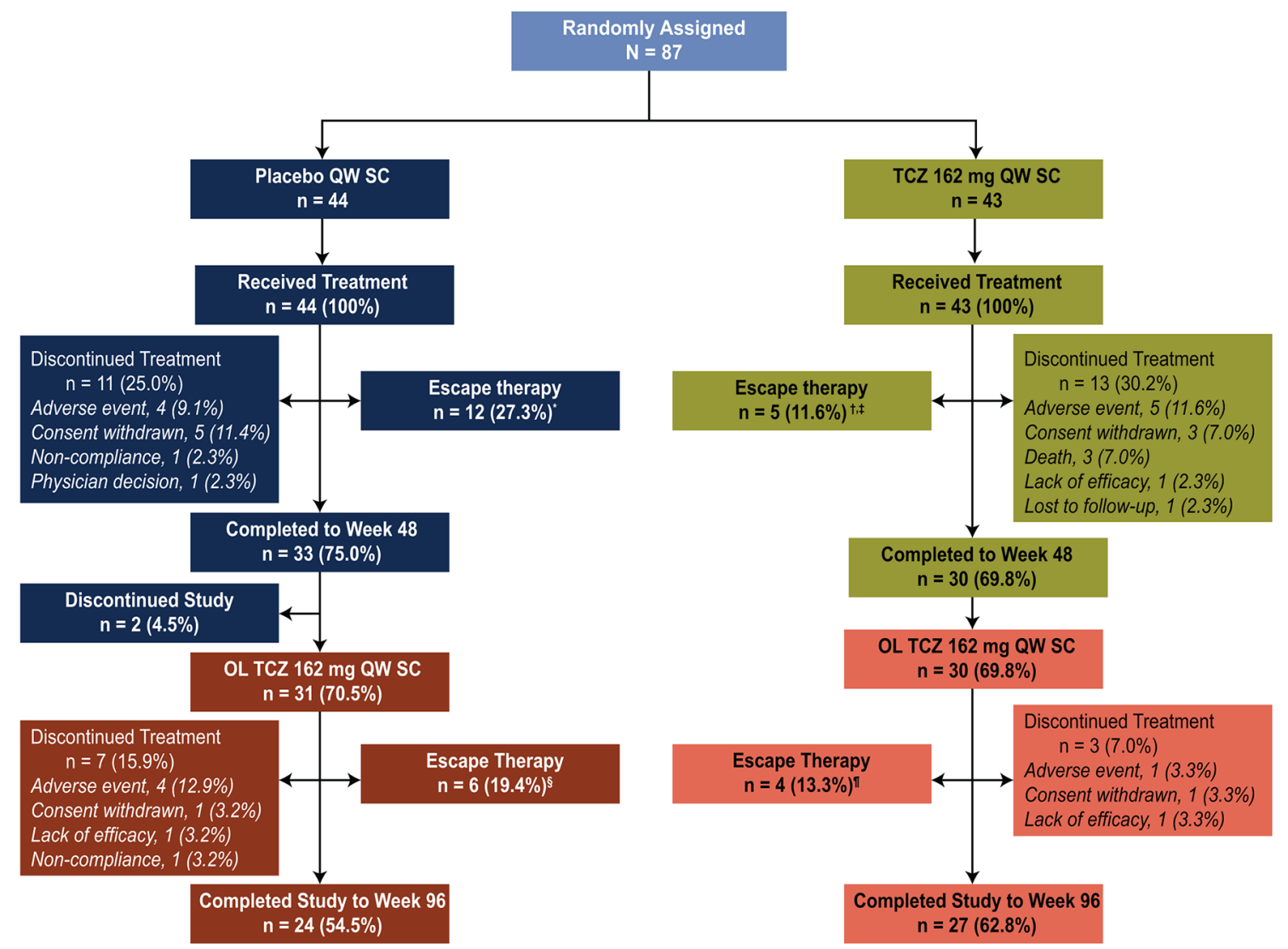

Figure 1 Patient disposition (intent-to-treat population). * Methotrexate, $n=5 ;$ hydroxychloroquine, $n=2 ;$ mycophenolate mofetil, $n=5$.

tMethotrexate, $n=2$; hydroxychloroquine, $n=2$; mycophenolate mofetil, $n=1$. $¥ 0$ ne patient who continued as an escape patient at week $48^{18}$ was later removed by the site and was not included at week 96 . §Methotrexate, $n=1$; hydroxychloroquine, $n=1$; mycophenolate mofetil, $n=4$ ( 1 patient who received mycophenolate mofetil in the double-blind period and received it again in the open-label period was not counted in the open-label period). १Hydroxychloroquine, $\mathrm{n}=2$; mycophenolate mofetil, $\mathrm{n}=2$. OL, open-label; QW, every week; SC, subcutaneously; TCZ, tocilizumab. 
Table 1 Baseline demographics and disease characteristics (safety population)

\begin{tabular}{|c|c|c|c|c|}
\hline & \multicolumn{2}{|c|}{ Patients randomly assigned in the double-blind period } & \multicolumn{2}{|c|}{ Patients who transitioned to the open-label period* } \\
\hline & $\begin{array}{l}\text { Placebo QW SC } \\
\mathrm{n}=44\end{array}$ & $\begin{array}{l}\text { Tocilizumab } 162 \mathrm{mg} \text { QW SC } \\
\mathrm{n}=43\end{array}$ & $\begin{array}{l}\text { Placebo- tocilizumab } 162 \mathrm{mg} \\
\text { QW SC } \\
\mathrm{n}=31\end{array}$ & $\begin{array}{l}\text { Continuous-tocilizumab } 162 \mathrm{mg} \\
\text { QW SC } \\
\mathrm{n}=30\end{array}$ \\
\hline Female, $n(\%)$ & $35(80)$ & $32(74)$ & $26(84)$ & $23(77)$ \\
\hline White, $n(\%)$ & $40(91)$ & $38(88)$ & $28(90)$ & $26(87)$ \\
\hline TJC28 & $7.4(8.5) \ddagger$ & $7.4(8.9)$ & $8.3(9.1)$ & $8.1(10.0)$ \\
\hline TJC28 $\geq 4, n(\%)$ & $21(49) \ddagger$ & $20(47)$ & $16(52)$ & $12(40)$ \\
\hline Overall HAQ-DI Score & $1.4(0.7)$ & $1.3(0.6) \S$ & $1.2(0.7)$ & $1.2(0.6) \emptyset$ \\
\hline Clinician Global VAS, mm & $60.9(15.2)$ & $64.1(15.1)$ & $57.9(15.2)$ & $62.5(15.7)$ \\
\hline Patient Global VAS, mm & $61.9(21.0)$ & $59.8(18.3)$ & $60.2(22.9)$ & $56.6(18.3)$ \\
\hline \%pDLCO (Hb corr) & $74(21) \ddagger$ & $73(19) \S$ & $75(23)^{* *}$ & $73(17)$ \\
\hline
\end{tabular}

All values are mean (SD) unless stated otherwise.

* Original baseline data for patients who entered the OL period.

†Possible scores: mRSS, 0-51; HAQ-DI, 0-3; Clinician Global VAS, 0-100; ULN for CRP, 3 mg/L.

$\neq \mathrm{n}=43$.

$\S n=42$.

In $=29$.

$* * \mathrm{n}=30$.

\%pDLCO (Hb corr), per cent predicted diffusing capacity of the lung for carbon monoxide corrected for haemoglobin; \%pFVC, per cent predicted forced vital capacity; CRP, C reactive protein; FACIT, Functional Assessment of Chronic Illness Therapy; HAQ-DI, Health Assessment Questionnaire-Disability Index; mRSS, modified Rodnan Skin Score; QW, every week; SC, subcutaneously; SSC, systemic sclerosis; TJC28, tender joint count based on 28 joints; ULN, upper limit of normal; VAS, Visual Analogue Scale.

assessed in all patients who received study drug and provided at least one safety assessment after treatment (safety population) and was summarised by treatment received. The study was not designed or powered for formal statistical comparison of the two treatment arms within the open-label period or with the original tocilizumab arm at week 48 because of inherent biases of openlabel results. However, 95\% CIs were calculated as descriptive statistics using the Pearson Clopper method for exact binomial, and CIs for rates of AEs were based on Poisson distribution. ${ }^{21}$ Data from escape patients were not censored.

\section{RESULTS}

\section{Patients}

Eighty-seven patients were enrolled in the faSScinate trial (figure 1); in the double-blind period, 44 patients were originally assigned to receive weekly subcutaneous placebo (placebo group) and 43 patients were originally assigned to receive weekly subcutaneous tocilizumab $162 \mathrm{mg}$ (tocilizumab group). At week $48,31(70.5 \%)$ patients originally assigned to double-blind placebo transitioned to open-label weekly tocilizumab $162 \mathrm{mg}$ (placebo-tocilizumab group) and $30(69.8 \%)$ patients originally assigned to double-blind tocilizumab transitioned to open-label weekly subcutaneous tocilizumab $162 \mathrm{mg}$ (continuous-tocilizumab group) until they completed the study or withdrew from treatment. Twenty-four $(54.5 \%)$ patients in the placebo-tocilizumab group and $27(62.8 \%)$ patients in the continuous-tocilizumab group completed week 96 . During the open-label period, five patients discontinued because of AEs (four patients in the placebo-tocilizumab group and one patient in the continuous-tocilizumab group). Other reasons for study withdrawal were non-compliance (one patient in the placebo-tocilizumab group), lack of efficacy (one patient in each treatment group) and patient consent withdrawn (one patient in each treatment group). Escape therapy was received by 18 patients originally assigned to receive placebo (12 in the placebo group during the double-blind period and 6 in the placebo-tocilizumab group during the openlabel period) and by 9 patients originally assigned to receive tocilizumab ( 5 in the tocilizumab group during the double-blind period and 4 in the continuous-tocilizumab group during the open-label period) (figure 1).

Baseline characteristics were similar between patients who were randomly assigned in the double-blind period and those who transitioned to open-label treatment, with the exception of HAQ-DI scores and CRP values, which were numerically lower, on average, in patients who transitioned to the open-label period (table 1).

\section{Efficacy}

Improvements in mRSS were observed during the double-blind period with tocilizumab treatment (mean (SD; 95\% CI) change from baseline to week 48 : $-5.6(9.1 ;-8.9$ to -2.4$))$. In addition to the -5.6 improvement from baseline to week 48 with tocilizumab treatment, further improvement was seen in the openlabel period, bringing the total mean improvement to -9.1 (8.7; -12.5 to -5.6 ) from baseline to week 96 (figure 2). Furthermore, patients in the placebo group experienced similar improvements after receiving open-label tocilizumab from week 48 to week 96 (figure 2) (mean (SD; 95\% CI) change from baseline -3.1 (6.3; -5.4 to -0.9$)$ to week 48 during double-blind placebo treatment and $-9.4(5.6 ;-11.8$ to -7.0$)$ to week 96 after 48 weeks of openlabel tocilizumab treatment). There were incremental improvements between weeks 48 and 96 in the proportions of patients who experienced improvements in mRSS of $\geq 20 \%, \geq 40 \%$ and 


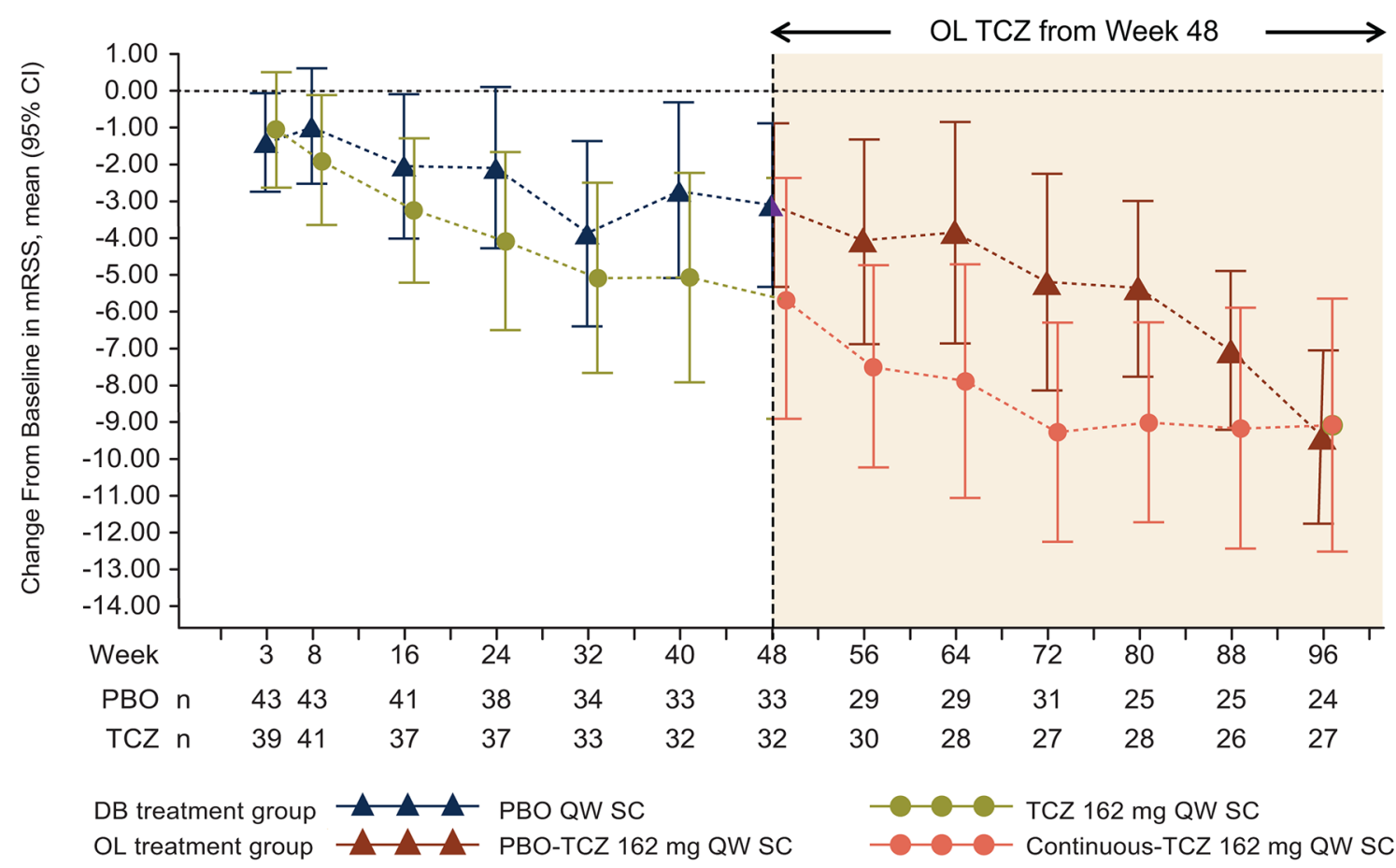

\begin{tabular}{|c|c|c|c|c|}
\hline \multicolumn{4}{|c|}{ PBO } & \multicolumn{2}{c|}{ TCZ } \\
\hline \multirow{2}{*}{ Wh } & $\begin{array}{c}\text { Mean (SD) [95\% Cl] } \\
\text { change from BL }\end{array}$ & $\begin{array}{c}\text { Mean (SD) [95\% CI] } \\
\text { observed score }\end{array}$ & $\begin{array}{c}\text { Mean (SD) [95\% Cl] } \\
\text { change from BL }\end{array}$ & $\begin{array}{c}\text { Mean (SD) [95\% CI] } \\
\text { observed score }\end{array}$ \\
\hline 24 & $-2.1(6.7)$ & $23.2(9.3)$ & $-4.1(7.3)$ & $21.8(9.9)$ \\
\hline \multirow{2}{*}{48} & {$[-4.3,0.1]$} & {$[20.2,26.3]$} & {$[-6.5,-1.7]$} & {$[18.5,25.1]$} \\
\hline 72 & $-3.1(6.3)$ & $22.3(8.1)$ & $-5.6(9.1)$ & $19.6(10.1)$ \\
\hline \multirow{2}{*}{96} & {$[-5.4,-0.9]$} & {$[19.4,25.1]$} & {$[-8.9,-2.4]$} & {$[15.9,23.2]$} \\
\hline & $-5.2(7.9)$ & $19.8(8.0)$ & $-9.3(7.5)$ & $16.0(9.1)$ \\
\hline & {$[-8.1,-2.3]$} & {$[16.9,22.7]$} & {$[-12.2,-6.3]$} & {$[12.4,19.7]$} \\
\hline & $-9.4(5.6)$ & $15.3(7.6)$ & $-9.1(8.7)$ & $16.2(9.8)$ \\
\hline
\end{tabular}

Figure 2 Mean change $(95 \% \mathrm{Cl})$ in mRSS from baseline to week 96 (intent-to-treat population; observed data). Negative values denote improvement. Patients randomly assigned to PBO $162 \mathrm{mg}$ QW SC received OL TCZ $162 \mathrm{mg}$ QW SC from week 48. BL, baseline; DB, double-blind; mRSS, modified Rodnan Skin Score; OL, open-label; PBO, placebo; \%pFVC, per cent predicted forced vital capacity; QW, every week; SC, subcutaneously; TCZ, tocilizumab.

$\geq 60 \%$ and change in mRSS equal to or greater than the MCID of 4.7 units in the continuous-tocilizumab group (table 2).

Improvements in Clinician Global VAS and patient-reported outcomes, as indicated by negative change in HAQ-DI, Clinician Global VAS, and Patient Global VAS and positive change in FACIT-Fatigue Score, observed at week 48 in the tocilizumab group were maintained through the open-label period in the continuous-tocilizumab group (table 2). Furthermore, greater improvements in patient-reported outcomes were observed in placebo-tocilizumab patients after they switched to tocilizumab during the open-label period than during the double-blind placebo period. Patients in the placebo group experienced mean (95\% CI) changes from baseline in HAQ-DI of 0.17 (0.05 to $0.30)$ after 48 weeks of double-blind placebo treatment and -0.29 $(-0.46$ to -0.13$)$ at week 96 after 48 weeks of open-label tocilizumab treatment (placebo-tocilizumab). Changes from baseline in Clinician Global VAS were $-7.69(-15.06$ to -0.32$)$ and -20.61 $(-29.52$ to -11.7$)$, respectively, changes in Patient Global VAS were $-4.03(-12.42$ to 4.36$)$ and $-23.75(-38.95$ to -3.46$)$, respectively, and changes in FACIT-Fatigue Scores were 1.37 ( -1.37 to 4.11$)$ and 11.26 (5.72 to 16.81 ), respectively.

Among patients who completed the study to week 96 (completers analysis), similar proportions in both treatment groups experienced worsening in $\% \mathrm{pFVC}$ (figure 3 ); $42 \%$ of patients in the placebo-tocilizumab group and $46 \%$ of patients in the continuous-tocilizumab group had absolute decreases $(>0)$ in \%pFVC during the openlabel period from weeks 48 to 96 compared with $83 \%$ of patients receiving placebo and $54 \%$ of patients receiving tocilizumab during the double-blind period from weeks 0 to 48 . During the open-label period, no patients in either treatment group who completed week 96 or withdrew experienced $>10 \%$ absolute decline in \%pFVC after receiving tocilizumab, in contrast to three in the placebo group and one in the tocilizumab group during the double-blind period.

\section{Safety}

SAE rates (95\% CIs) were $76.1(50.6-110.0)$ in the placebo group and 66.7 (42.3-100.1) in the tocilizumab group by week 
Table 2 Change from baseline to week 48 (double-blind period) or week 96 (including open-label period) in exploratory end points (intent-totreat population; observed data)

\begin{tabular}{|c|c|c|c|c|}
\hline & \multicolumn{2}{|c|}{ Double-blind period, week 48} & \multicolumn{2}{|c|}{ Open-label period, week 96} \\
\hline & $\begin{array}{l}\text { Placebo } \\
\text { QW SC } \\
n=44\end{array}$ & $\begin{array}{l}\text { Tocilizumab } \\
162 \mathrm{mg} \text { QW SC } \\
\mathrm{n}=43\end{array}$ & $\begin{array}{l}\text { Placebo- tocilizumab } \\
162 \mathrm{mg} \text { QW SC } \\
\mathrm{n}=31\end{array}$ & $\begin{array}{l}\text { Continuous-tocilizumab } \\
162 \mathrm{mg} \text { QW SC } \\
\mathrm{n}=30\end{array}$ \\
\hline \multicolumn{5}{|l|}{ Change from baseline in $\mathrm{mRSS}, \mathrm{n}(\%(95 \% \mathrm{Cl}))^{*}$} \\
\hline$\geq 20 \%$ & $13(29.5[16.8$ to 45.2$])$ & $18(41.9[27.0$ to 57.9$])$ & $18(40.9[26.3$ to 56.8$])$ & 22 (51.2 [35.5 to 66.7$])$ \\
\hline$\geq 40 \%$ & $3(6.8[1.4$ to 18.7$])$ & $10(23.3[11.8$ to 38.6$])$ & $13(29.5[16.8$ to 45.2$])$ & 15 (34.9 [21.0 to 50.9$])$ \\
\hline$\geq 60 \%$ & $0(0.0[0.0$ to 8.0$])$ & $5(11.6[3.9$ to 25.1$])$ & $7(15.9[6.6$ to 30.1$])$ & $6(14.0[5.3$ to 27.9$])$ \\
\hline$\geq 4.7$ units $(M C I D)^{20}$ & $\begin{array}{l}12(27.3[15.0,42.8]) \\
n=33\end{array}$ & $\begin{array}{l}18(41.9[27.0,57.9]) \\
n=32\end{array}$ & $\begin{array}{l}19(43.2[28.3,59.0]) \\
n=24\end{array}$ & $\begin{array}{l}22(51.2[35.5,66.7]) \\
\mathrm{n}=27\end{array}$ \\
\hline TJC28, mean $(95 \% \mathrm{Cl})$ change from baseline & $-0.97(-2.85$ to 0.91$)$ & $-2.28(-4.16$ to -0.40$)$ & $-4.88(-7.99$ to -1.76$)$ & $-3.39(-6.14$ to -0.65$)$ \\
\hline$[\min , \max ]$ & $\begin{array}{l}{[-16,12]} \\
n=33\end{array}$ & $\begin{array}{l}{[-14,9]} \\
n=32\end{array}$ & $\begin{array}{l}{[-23,2]} \\
n=24\end{array}$ & $\begin{array}{l}{[-25,7]} \\
\mathrm{n}=28\end{array}$ \\
\hline $\begin{array}{l}\text { HAQ-DI, mean }(95 \% \mathrm{Cl}) \text { change from } \\
\text { baselinet }\end{array}$ & $0.17(0.05$ to 0.30$)$ & $-0.01(-0.25$ to 0.23$)$ & $-0.29(-0.46$ to -0.13$)$ & $-0.13(-0.33$ to 0.08$)$ \\
\hline$[\mathrm{min}, \max ]$ & $\begin{array}{l}{[-0.63,0.88]} \\
\mathrm{n}=34\end{array}$ & $\begin{array}{l}{[-1.13,1.75]} \\
\mathrm{n}=31\end{array}$ & $\begin{array}{l}{[-1.25,0.50]} \\
\mathrm{n}=24\end{array}$ & $\begin{array}{l}{[-1.25,1.38]} \\
\mathrm{n}=27\end{array}$ \\
\hline $\begin{array}{l}\text { Clinician Global VAS, mean }(95 \% \mathrm{Cl}) \text { change } \\
\text { from baselinet }\end{array}$ & $-7.69(-15.06$ to -0.32$)$ & $-18.57(-26.89$ to -10.25$)$ & $-20.61(-29.52$ to -11.7$)$ & $-21.30(-31.05$ to -11.54$)$ \\
\hline$[\min , \max ]$ & $\begin{array}{l}{[-45,39]} \\
n=32\end{array}$ & $\begin{array}{l}{[-60,14]} \\
n=30\end{array}$ & $\begin{array}{l}{[-57,21]} \\
n=23\end{array}$ & $\begin{array}{l}{[-73,14]} \\
n=27\end{array}$ \\
\hline $\begin{array}{l}\text { Patient Global VAS, mean }(95 \% \mathrm{Cl}) \text { change } \\
\text { from baselinet }\end{array}$ & $-4.03(-12.42$ to 4.36$)$ & $-9.13(-18.68$ to 0.43$)$ & $-23.75(-38.95$ to -8.55$)$ & $-11.11(-18.75$ to -3.46$)$ \\
\hline$[\min , \max ]$ & $\begin{array}{l}{[-64,57]} \\
n=34\end{array}$ & $\begin{array}{l}{[-59,36]} \\
n=32\end{array}$ & $\begin{array}{l}{[-90,38]} \\
n=24\end{array}$ & $\begin{array}{l}{[-44,33]} \\
\mathrm{n}=28\end{array}$ \\
\hline $\begin{array}{l}\text { FACIT-Fatigue score, mean }(95 \% \mathrm{Cl}) \text { change } \\
\text { from baselinet }\end{array}$ & $1.37(-1.37$ to 4.11$)$ & 3.69 (0.34 to 7.04$)$ & $11.26(5.72$ to 16.81$)$ & 4.15 (1.51 to 6.79$)$ \\
\hline$[\min , \max ]$ & $\begin{array}{l}{[-18.0,15.0]} \\
n=32\end{array}$ & $\begin{array}{l}{[-15.0,22.0]} \\
n=32\end{array}$ & $\begin{array}{l}{[-15.0,29.0]} \\
n=23\end{array}$ & $\begin{array}{l}{[-10.0,19.0]} \\
n=27\end{array}$ \\
\hline $\begin{array}{l}\text { Pruritus 5-D Itch Score, mean }(95 \% \mathrm{Cl}) \\
\text { change from baselinet }\end{array}$ & $-1.87(-3.26$ to -0.48$)$ & $-2.03(-3.91$ to -0.16$)$ & $-4.43(-6.32$ to -2.55$)$ & $-3.23(-5.38$ to -1.09$)$ \\
\hline$[\min , \max ]$ & $\begin{array}{l}{[-10,5]} \\
n=30\end{array}$ & $\begin{array}{l}{[-15,7]} \\
\mathrm{n}=30\end{array}$ & $\begin{array}{l}{[-14,1]} \\
\mathrm{n}=23\end{array}$ & $\begin{array}{l}{[-14,9\}} \\
n=26\end{array}$ \\
\hline $\begin{array}{l}\% \mathrm{pFVC} \text {, mean }(95 \% \mathrm{Cl}) \text { change from } \\
\text { baseline }\end{array}$ & $-0.06(-0.10$ to -0.03$)$ & $-0.02(-0.04$ to 0.00$)$ & $-0.03(-0.07$ to 0.01$)$ & $-0.01(-0.03$ to 0.02$)$ \\
\hline$[\min , \max ]$ & $\begin{array}{l}{[-0.33,0.13]} \\
\mathrm{n}=32\end{array}$ & $\begin{array}{l}{[-0.15,0.04]} \\
\mathrm{n}=30\end{array}$ & $\begin{array}{l}{[-0.25,0.20]} \\
\mathrm{n}=25\end{array}$ & $\begin{array}{l}{[-0.15,0.15]} \\
\mathrm{n}=28\end{array}$ \\
\hline $\begin{array}{l}\% \mathrm{pDLCO}(\mathrm{Hb} \text { corr), mean }(95 \% \mathrm{Cl}) \text { change } \\
\text { from baseline }\end{array}$ & $-0.03(-0.07$ to 0.01$)$ & $-0.03(-0.06$ to 0.00$)$ & $-0.03(-0.10$ to 0.05$)$ & $-0.03(-0.08$ to 0.01$)$ \\
\hline$[\min , \max ]$ & $\begin{array}{l}{[-0.23,0.28]} \\
n=31\end{array}$ & $\begin{array}{l}{[-0.26,0.12]} \\
n=27\end{array}$ & $\begin{array}{l}{[-0.71,0.25]} \\
\mathrm{n}=24\end{array}$ & $\begin{array}{l}{[-0.25,0.21]} \\
\mathrm{n}=25\end{array}$ \\
\hline
\end{tabular}

$\mathrm{n}$ denotes number of patients with valid assessments at the time point. Escape data were not censored.

*Percentages were calculated based on $n=43$ (tocilizumab) and $n=44$ (placebo), the intent-to-treat population; thus, patients with missing change in mRSS Scores were considered non-responders.

†Negative change from baseline indicated improvement for all efficacy measures except FACIT-Fatigue, FVC and DLCO, for which positive change from baseline indicated improvement.

\%pDLCO ( $\mathrm{Hb}$ corr), per cent predicted diffusing capacity of lung for carbon monoxide corrected for haemoglobin; \%pFVC, per cent predicted forced vital capacity; FACIT, Functional Assessment of Chronic Illness Therapy; HAQ-DI, Health Assessment Questionnaire-Disability Index; max, maximum; MCID, minimal clinically important difference; min, minimum; mRSS, modified Rodnan Skin Score; QW, every week; SC, subcutaneously; TJC28, tender joint count based on 28 joints; VAS, Visual Analogue Scale.

48 compared with 36.0 (18.0-64.4) in the placebo-tocilizumab group and 16.5 (5.4-38.5) in the continuous-tocilizumab group from week 48 to week 96 (table 3). Infections were the most frequently reported AEs and SAEs during double-blind tocilizumab treatment and in placebo patients who transitioned to open-label tocilizumab. In the placebo-tocilizumab group, rates of serious infection increased after the switch to open-label tocilizumab; the rate $(95 \% \mathrm{CI})$ of serious infections was 10.9 (3.0-27.9) per 100 PY during the 48 weeks of double-blind placebo treatment compared with $19.6(7.2-42.7)$ per $100 \mathrm{PY}$ from week 48 to 96 , with four patients (12.9\%) in this group reporting at least one serious infection after switching to openlabel tocilizumab (see online supplementary appendix table 1 for details of serious infections). Patients in the tocilizumab group had a serious infection rate of 34.8 (95\% CI 18.0 to 60.8 ) per 100 PY by week 48. No serious infections were reported after the switch from double-blind to open-label tocilizumab (continuous-tocilizumab).

No deaths were reported during the open-label period in either treatment group, and no serious hepatic AEs, anaphylactic reactions, gastrointestinal perforations or demyelination SAEs were reported during the 96-week treatment period. Changes in laboratory parameters of interest for tocilizumab, including alanine aminotransferase (ALT) and aspartate aminotransferase (AST) levels, neutrophil counts and platelet counts, were usually $\leq 5 \times$ the upper limit of normal (ULN) over the 96-week treatment period. 


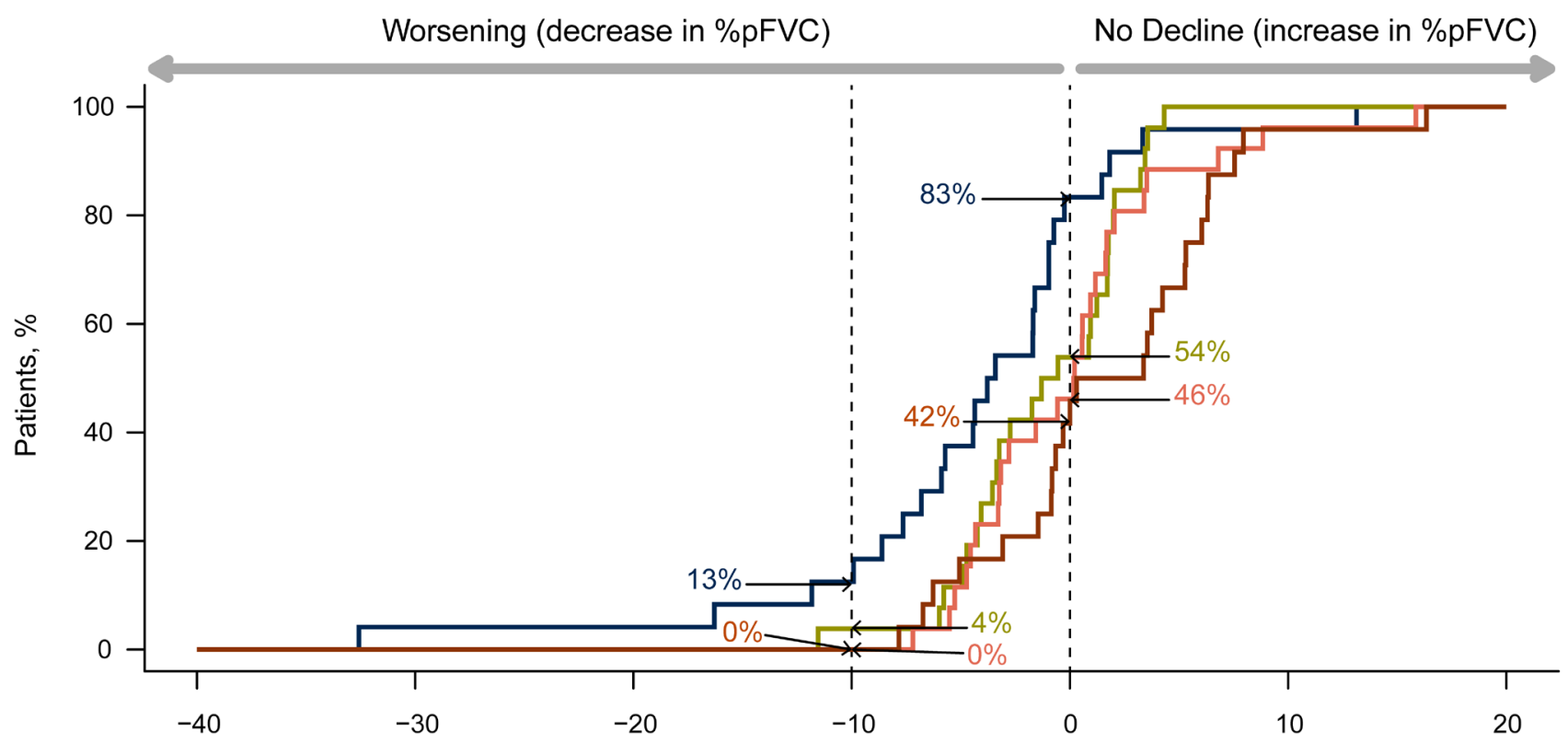

\%pFVC Change From Baseline

Weeks $0-48$ (DB)

Weeks 48-96 (OL)

- PBO QW SC $(n=24) \quad-\quad T C Z 162 \mathrm{mg} \mathrm{QW} \mathrm{SC}(n=26)$

— PBO -TCZ $162 \mathrm{mg}$ QW SC (n=24) Continuous-TCZ $162 \mathrm{mg} \mathrm{QW} \mathrm{SC}(\mathrm{n}=26)$

\begin{tabular}{|c|c|c|c|c|}
\hline \multirow{2}{*}{} & \multicolumn{2}{|c|}{ Weeks 0-48 (DB) } & \multicolumn{2}{c|}{ Weeks 48-96 (OL) } \\
\cline { 2 - 5 } & $\begin{array}{c}\text { PBO } \\
\text { QW SC } \\
(\mathbf{n = 2 4 )}\end{array}$ & $\begin{array}{c}\text { TCZ 162 } \\
\text { mg QW } \\
\text { SC } \\
(\mathbf{n = 2 6 )}\end{array}$ & $\begin{array}{c}\text { PBO-TCZ } \\
\mathbf{1 6 2} \mathbf{~ m g ~ Q W ~} \\
\text { SC } \\
(\mathbf{n}=\mathbf{2 4})\end{array}$ & $\begin{array}{c}\text { Continuous- } \\
\text { TCZ 162 } \\
\text { mg QW SC } \\
\text { (n = 26) }\end{array}$ \\
\hline \%pFVC change from baseline, $\mathrm{n}(\%)[95 \% \mathrm{Cl}]$ \\
\hline Absolute decrease $>0$ & $20(83)$ & $14(54)$ & $10(42)$ & $12(46)$ \\
& {$[63,95]$} & {$[33,73]$} & {$[22,63]$} & {$[27,67]$} \\
\hline Absolute decrease $>10 \%$ & $3(13)$ & $1(4)$ & $0(0)$ & $0(0)$ \\
{$[3,32]$} & {$[0,20]$} & {$[0,14]$} & {$[0,13]$} \\
\hline
\end{tabular}

Figure 3 Cumulative distribution plot of change from baseline in \%pFVC (completers analysis). Data for TCZ $162 \mathrm{mg}$ QW SC and PBO $162 \mathrm{mg}$ QW SC treatment groups show change from baseline to week 48. Patients receiving PBO-TCZ $162 \mathrm{mg}$ QW SC and continuous-TCZ $162 \mathrm{mg}$ QW SC started OL TCZ from week 48 (mean (SD) \%pFVC at week 48 was 0.78 (0.14) for the PBO group and 0.80 (0.11) for the TCZ group), and change from week 48 to week 96 is shown. Only patients with data at week 96 are included in any arm (completers); one completer had a missing FVC assessment at week 96 and was excluded from the completers analysis. DB, double-blind; OL, open-label; PBO, placebo; \%pFVC, per cent predicted forced vital capacity;

QW, every week; SC subcutaneously; TCZ, tocilizumab.

ALT elevation $>5 \times$ ULN was reported in one patient receiving placebo and one patient receiving tocilizumab during the doubleblind period and one placebo-tocilizumab patient after switching to open-label tocilizumab. AST elevation $>5 \times$ ULN was reported in one patient receiving placebo during the double-blind period (see online supplementary appendix table 2).

\section{DISCUSSION}

The phase II faSScinate Study was the first double-blind, randomised controlled trial to show evidence of a potential disease-modifying effect in patients with SSc. By week 48, at the end of the double-blind period of the study, treatment with tocilizumab was associated with clinically relevant, though not statistically significant, improvements in skin thickness measured by mRSS and lung function measured by $\%$ pFVC. ${ }^{18}$ It has been suggested that tocilizumab may be the first efficient, molecularly targeted treatment for patients with SSc. ${ }^{22}$

Results from the open-label period of the faSScinate trial show that patients originally assigned to receive placebo in the doubleblind period who transitioned to open-label tocilizumab at week 48 experienced improvements in mRSS by week 96 that were similar to those of patients who received tocilizumab throughout the study. Furthermore, patients originally assigned to receive tocilizumab during the double-blind period maintained and continued the improvements in mRSS observed during the first 48 weeks of treatment on receiving another 48 weeks of openlabel tocilizumab. Although the mean change in mRSS appeared to flatten from week 72 in the continuous-tocilizumab group, 
Table 3 Adverse events (AEs, safety population)

\begin{tabular}{|c|c|c|c|c|}
\hline & \multicolumn{2}{|l|}{ Double-blind period } & \multicolumn{2}{|l|}{ Open-label period } \\
\hline & $\begin{array}{l}\text { Placebo } \\
\text { QW SC } \\
\mathrm{n}=44\end{array}$ & $\begin{array}{l}\text { Tocilizumab } \\
162 \mathrm{mg} \text { QW SC } \\
\mathrm{n}=43\end{array}$ & $\begin{array}{l}\text { Placebo-tocilizumab } \\
162 \mathrm{mg} \mathrm{QW} \mathrm{SC} \\
\mathrm{n}=31\end{array}$ & $\begin{array}{l}\text { Continuous-tocilizumab } \\
162 \mathrm{mg} \text { QW SC } \\
\mathrm{n}=30\end{array}$ \\
\hline Exposure, PY & 36.8 & 34.5 & 30.6 & 30.3 \\
\hline $\mathrm{AEs}, \mathrm{n}$ & 244 & 283 & 126 & 153 \\
\hline Rate/100 PY (95\% Cl) & 663.5 (582.9 to 752.2 ) & $820.6(727.8$ to 922.0$)$ & 412.4 (343.5 to 491.0$)$ & $504.4(427.6$ to 590.9$)$ \\
\hline SAEs, $\mathrm{n}$ & 28 & 23 & 11 & 5 \\
\hline Rate/100 PY (95\% Cl) & 76.1 (50.6 to 110.0$)$ & $66.7(42.3$ to 100.1$)$ & 36.0 (18.0 to 64.4$)$ & $16.5(5.4$ to 38.5$)$ \\
\hline Patients with $\geq 1 \mathrm{SAE}, \mathrm{n}(\%)$ & $16(36.4)$ & $14(32.6)$ & $7(22.6)$ & $4(13.3)$ \\
\hline Patients with $\geq 1$ serious infection, $n(\%)^{*}$ & $3(6.8)$ & $9(20.9)$ & $4(12.9)$ & 0 \\
\hline AEs leading to death, $n$ & 1 & 3 & 0 & 0 \\
\hline Rate/100 PY & 2.72 & 8.70 & 0.00 & 0.00 \\
\hline Patients with AEs leading to withdrawal, $n(\%)$ & $5(11.4)$ & $6(14.0)$ & $4(12.9) \dagger$ & 0 \\
\hline Rate/100 PY & 13.60 & 17.40 & 13.09 & 0.00 \\
\hline Patients with injection site reactions, $\mathrm{n}^{*}$ & $2(4.5)$ & $3(7.0)$ & $4(12.9)$ & $1(3.3)$ \\
\hline \multicolumn{5}{|c|}{ SAEs according to system organ class, $\neq$ number of events (rate/100 PY [95\% CI]) } \\
\hline Infections and infestations & $4(10.9[3.0$ to 27.9$])$ & $12(34.8[18.0$ to 60.8$])$ & $6(19.6[7.2$ to 42.7$])$ & $0(0.0[0.0$ to 12.2$])$ \\
\hline Cardiac disorders & $5(23.6[4.4$ to 31.7$])$ & $1(2.9[0.1$ to 16.2$])$ & $0(0.0[0.0$ to 12.1$])$ & $1(3.3[0.1$ to to 18.4$])$ \\
\hline Gastrointestinal disorders & $6(16.3[6.0$ to 35.5$])$ & $1(2.9[0.1$ to 16.2$])$ & $0(0.0[0.0$ to 12.1$])$ & $0(0.0[0.0$ to 12.2$])$ \\
\hline Musculoskeletal and connective tissue disorders & $2(5.4[0.7$ to 19.7$])$ & $2(5.8[0.7$ to 21.0$])$ & $1(3.3[0.1$ to 18.2$])$ & $0(0.0[0.0$ to 12.2$])$ \\
\hline Skin and subcutaneous tissue disorders & $2(5.4[0.7$ to 19.7$])$ & $2(5.8[0.7$ to 21.0$])$ & $0(0.0[0.0$ to 12.1$])$ & $1(3.3[0.1$ to 18.4$])$ \\
\hline Vascular disorders & $4(10.9[3.0$ to 27.9$])$ & $1(2.9[0.1$ to 16.2$])$ & $0(0.0[0.0$ to 12.1$])$ & $0(0.0[0.0$ to 12.2$])$ \\
\hline Blood and lymphatic system disorders & $1(2.7[0.1$ to 15.2$])$ & $1(2.9[0.1$ to 16.2$])$ & $1(3.3[0.1$ to 18.2$])$ & $0(0.0[0.0$ to 12.2$])$ \\
\hline Renal and urinary disorders & $2(5.4[0.7$ to 19.7$])$ & $0(0.0[0.0$ to 10.7$])$ & $1(3.3[0.1$ to 18.2$])$ & $0(0.0[0.0$ to 12.2$])$ \\
\hline General disorders and administration site conditions & $0(0.0[0.0$ to 10.0$])$ & $2(5.8[0.7$ to 21.0$])$ & $0(0.0[0.0$ to 12.1$])$ & $0(0.0[0.0$ to 12.2$])$ \\
\hline Neoplasms, benign, malignant and unspecified & $0(0.0[0.0$ to 10.0$])$ & $0(0.0[0.0$ to 10.7$])$ & 1 (3.3 [0.1 to 18.2$])$ & $1(3.3[0.1$ to 18.4$])$ \\
\hline Nervous system disorders & $2(5.4[0.7$ to 19.7$])$ & $0(0.0[0.0$ to 10.7$])$ & $0(0.0[0.0$ to 12.1$])$ & $0(0.0[0.0$ to 12.2$])$ \\
\hline Endocrine disorders & $0(0.0[0.0$ to 10.0$])$ & $0(0.0[0.0$ to 10.7$])$ & $0(0.0[0.0$ to 12.1$])$ & $1(3.3[0.1$ to 18.4$])$ \\
\hline Psychiatric disorders & $0(0.0[0.0$ to 10.0$])$ & $1(2.9[0.1$ to 16.2$])$ & $0(0.0[0.0$ to 12.1$])$ & $0(0.0[0.0$ to 12.2$])$ \\
\hline Reproductive system and breast disorders & $0(0.0[0.0$ to 10.0$])$ & $0(0.0[0.0$ to 10.7$])$ & $0(0.0[0.0$ to 12.1$])$ & 1 (3.3 [0.1 to 18.4$])$ \\
\hline Respiratory, thoracic and mediastinal disorders & $0(0.0[0.0$ to 10.0$])$ & $0(0.0[0.0$ to 10.7$])$ & 1 (3.3 [0.1 to 18.2$])$ & $0(0.0[0.0$ to 12.2$])$ \\
\hline
\end{tabular}

${ }^{*}$ Multiple occurrences in the same patient are counted once.

†Osteomyelitis (one case serious, one case not serious), scleroderma renal crisis and breast cancer metastatic.

$¥$ According to the Medical Dictionary for Regulatory Activities, version 18.0.

AEs, adverse events; PY, patient-years; QW, every week; SAEs, serious adverse events; SC, subcutaneously.

there were improvements for individual patients between weeks 72 and 96 . Of the 27 patients receiving continuous tocilizumab who completed the study through week 96, 14/27 (52\%) had further, primarily modest, improvements (range, -1 to -8 change in mRSS). However, there were two outliers who experienced considerable worsening ( +9 and +14 change in mRSS) during this period. Overall, this culminates in a flattened average response. The potential for improvement may be more limited at this time point; $7 / 27(26 \%)$ patients among the continuous tocilizumab completers had observed mRSS scores $\leq 9$ at week 72 compared with $2 / 24(8 \%)$ among the placebo-tocilizumab group.

Improvements from weeks 48 to 96 in mRSS were supported by improvements in patient-reported outcomes, including HAQ-DI, Patient Global VAS and FACIT-Fatigue Scores, observed in patients initially assigned to placebo who transitioned to open-label tocilizumab and were comparable to those of patients who received tocilizumab continuously, consistent with trends observed with tocilizumab treatment during the doubleblind period. ${ }^{18}$ Consistent as well with exploratory analyses in the double-blind period showing fewer tocilizumab-treated $(10 \%)$ than placebo-treated (23\%) patients experienced absolute decline $(>10 \%)$ in $\%$ pFVC after 48 weeks, ${ }^{18}$ no patients who completed week 96 of the study experienced $>10 \%$ decline in \%pFVC during the open-label period while receiving tocilizumab. Of note, the primary end point was change in mRSS, and, at the time the study was designed, the patient populations had not been enriched for patients with SSc-associated interstitial lung disease.

Safety results over the 96-week treatment period were consistent with the known safety profile of tocilizumab; infections were the most frequently reported AEs and SAEs, and an increased rate of serious infections was observed after patients transitioned from placebo to tocilizumab. AEs tended to occur more frequently in the first few months after patients transitioned from placebo to tocilizumab but less frequently in longerterm follow-up. Infections were the most frequently reported SAEs in clinical trials of tocilizumab in patients with rheumatoid arthritis (RA). ${ }^{23}{ }^{24}$ Rates of SAEs and serious infections in this study in patients with SSc were approximately five times and eight times higher, respectively, than those reported in patients with RA, ${ }^{23}{ }^{24}$ which is expected given the high morbidity and mortality in patients with SSc. ${ }^{1}$ The frequencies of SAEs and serious infections observed in faSScinate are consistent with those in other SSc studies. ${ }^{25-27}$ Patients with SSc may be prone to digital ulcers, ${ }^{1}$ and complications of digital ulcers occur in $15 \%$ 
of patients with SSc. ${ }^{28}$ The occurrence of two cases of infected digital ulcers and one of osteomyelitis in patients who transitioned from placebo to open-label tocilizumab suggested that tocilizumab may increase infections in patients with SSc-associated digital ulcers, likely over pressure areas such as proximal interphalangeal joints.

The present study had some important limitations. First, all patients received open-label tocilizumab after week 48; therefore, the data collected during the open-label period were uncontrolled. There was a high discontinuation rate. During the open-label period, 7 of the 31 (23\%) patients originally assigned to placebo who entered the open-label period and 3 of the $30(10 \%)$ patients originally assigned to tocilizumab who entered the open-label period withdrew from the study. The discontinuation rate from 48 to 96 weeks (16\%) was lower than it was in the first 48 weeks of the study $(28 \%)$. Overall, $63 \%$ of patients originally assigned to receive tocilizumab and $55 \%$ of patients originally assigned to receive placebo completed the full 96 weeks of treatment. It is likely that patients who completed week 48 and entered the open-label period were less ill or responded better to treatment and perhaps had already experienced more improvement. This selection bias is a common problem associated with open-label, long-term extension studies. ${ }^{29}$ Withdrawal of patients who experience AEs leads to the selection of healthier patients, which should be considered when interpreting the longer-term rates of AEs and SAEs. Second, patients with elevated acute-phase reactants were enrolled in this study; therefore, further studies may be needed to investigate the efficacy and safety of tocilizumab in other patient subsets. Third, given the limited numbers of patients with serious infections, analysis of the data to identify potential risk factors, in particular for any interaction of risk factors with tocilizumab, would be underpowered and was not performed. A phase III study with a larger sample size is under way. Last, another limitation is that the study was not designed or powered for formal statistical comparison of the two treatment arms during the open-label period, and formal testing of this exploratory data was not prespecified. For the same reason, a comparison of placebo patients who completed the openlabel phase with those in the tocilizumab treatment arm at week 48 is not appropriate. Therefore, although trends can be observed, comparative analyses could not be interpreted in a meaningful way, and formal statistical testing was not feasible.

No disease-modifying therapies have been approved for the treatment of patients with SSc, but some may control symptoms. Treatment options for patients with SSc are largely dependent on the organs affected. ${ }^{30} 31$ For example, cyclophosphamide has demonstrated improvement $t^{32}$ or trends for improvement ${ }^{33}$ in lung function in patients with SSc and interstitial lung disease, though its use has been associated with significant toxicity. ${ }^{30}$ Similarly, stem cell transplantation has resulted in improvements in skin fibrosis and prevention of lung decline and mortality but is associated with significant costs and risks. ${ }^{34-36}$ Methotrexate has demonstrated trends for improvement in skin scores in randomised controlled trials in patients with early SSc. ${ }^{38}$ Recently, MMF has shown efficacy similar to that of cyclophosphamide for lung and skin fibrosis. ${ }^{39}{ }^{40}$ Tocilizumab may be the first targeted agent to show benefit in the amelioration of skin sclerosis and the prevention of pulmonary decline in patients with SSc. ${ }^{18}$

Overall, the open-label results of the faSScinate study support observations reported from the double-blind period in that the placebo and tocilizumab groups improved similarly when placebo patients were switched to active treatment. Further studies are required to investigate the efficacy and safety of tocilizumab in the treatment of patients with SSc and to determine whether tocilizumab produces significant improvement in skin sclerosis and stabilisation of lung function. A double-blind, phase III randomised controlled trial (NCT02453256) will investigate the efficacy and safety of tocilizumab compared with placebo in a 48-week doubleblind period and a 48-week open-label period to further investigate the findings of the phase II faSScinate trial.

In conclusion, together with the results from the first 48 weeks of double-blind treatment, ${ }^{18}$ results from the open-label period of the faSScinate trial suggest that treatment with tocilizumab is associated with benefits for skin fibrosis, lung fibrosis and physical function in patients with SSc but increased risk for serious infections. Tocilizumab may be a promising targeted therapy for patients with progressive SSc who have few treatment options.

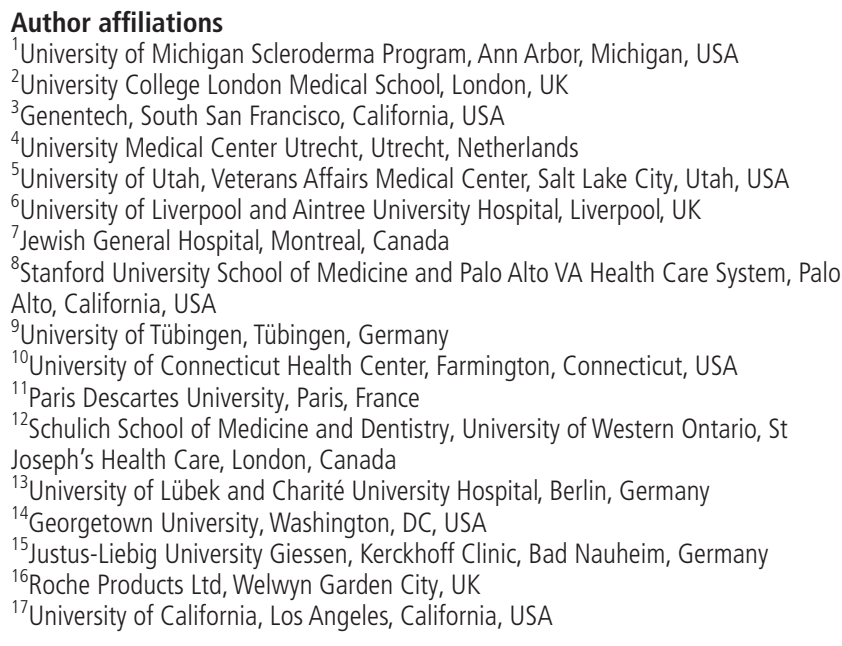

Acknowledgements The authors thank Jennifer Adlington, PhD, and Sara Duggan, $\mathrm{PhD}$, for professional writing and editorial assistance in preparing the first draft of the manuscript, on behalf of F Hoffmann-La Roche Ltd.

Contributors All authors were involved in drafting the article or revising it critically for important intellectual content, approved the final draft to be published, and agree be accountable for all aspects of the work in ensuring that questions related to the accuracy or integrity of any part of the work are appropriately investigated and resolved. DK, CPD and AJ contributed to the conception and design of the study and the acquisition, analysis and interpretation of data. CJFL and YA contributed to the analysis and interpretation of data. JMvL, TMF, MB, LC, GF, SL and VS contributed to acquisition of data. MEA and GR contributed to conception and design of the study and acquisition of data. JEP and LB contributed to acquisition, analysis and interpretation of data. UM-L, HS, JS and DEF contributed to conception and design of the study and analysis and interpretation of data.

Funding This study was funded by Roche. Funding for manuscript preparation was provided by F Hoffmann-La Roche Ltd.

Competing interests DK reports personal fees from Actelion, BoehringerIngelheim, Covis, CSL Behring, Corbus, Cytori, EMD Serono, Genentech/Roche, GSK, Inventiva, Medac, Sanofi-Aventis and UCB; grants from BMS, Bayer and Pfizer; stocks in Eicos Sciences, Inc, during the conduct of the study; and personal fees from Astra Zeneca outside the submitted work. CPD reports personal fees from Roche, Actelion, EMD Serono, Sanofi and Boehringer Ingelheim; grants and personal fees from GSK and Inventiva; and grants from CSL Behring during the conduct of the study. CJFL is an employee of Genentech. JMvL reports grants and personal fees from MSD and Genentech and personal fees from BMS, Eli Lilly and Pfizer outside the submitted work. MEA reports funding to Hospital Trust from Roche during the conduct of the study and personal fees from Actelion Pharmaceuticals outside the submitted work. YA has received research support and grants related to the submitted work from BMS, Roche/Genentech, Inventiva, Pfizer and Sanofi; consulting honoraria and personal fees related to the current work from Actelion, Bayer, Boehringer, Roche/Genentech, Galapagos, Inventiva, Medac, Pfizer, Sanofi, Servier and UCB; and personal fees outside the submitted work from Sandoz. JEP reports funding for the current trial by Roche. GR has received lecturer's fees from Roche and Chugai outside the submitted work. UM-L is a speaker and advisor to Roche and Chugai related to the submitted work. HS is an employee of and has non-voting shares in Roche Products Limited. LB is an employee of Roche. JS is an employee of Genentech. AJ is an employee of Genentech, owns stock and options in Roche and owns a patent for subcutaneous tocilizumab. All other authors have no conflicts of interest to disclose. 
Patient consent Obtained

Ethics approval Informed consent forms and other recruitment materials were approved by the Institutional Review Board/Ethics Committee before study initiation. The study was conducted in compliance with the International Conference on Harmonisation for Good Clinical Practice Guidelines and the Declaration of Helsinki.

Provenance and peer review Not commissioned; externally peer reviewed.

Open Access This is an Open Access article distributed in accordance with the Creative Commons Attribution Non Commercial (CC BY-NC 4.0) license, which permits others to distribute, remix, adapt, build upon this work non-commercially, and license their derivative works on different terms, provided the original work is properly cited and the use is non-commercial. See: http://creativecommons.org/ licenses/by-nc/4.0/

(C) Article author(s) (or their employer(s) unless otherwise stated in the text of the article) 2018. All rights reserved. No commercial use is permitted unless otherwise expressly granted.

\section{REFERENCES}

1 Nikpour M, Stevens WM, Herrick AL, et al. Epidemiology of systemic sclerosis. Best Pract Res Clin Rheumatol 2010;24:857-69.

2 Denton CP. Systemic sclerosis: from pathogenesis to targeted therapy. Clin Exp Rheumatol 2015;33(4 Suppl 92):S3-7.

3 Denton CP, Khanna D. Systemic sclerosis. The Lancet 2017;50140-6736(17)30933-9. [Epub ahead of print].

4 loannidis JP, Vlachoyiannopoulos PG, Haidich AB, et al. Mortality in systemic sclerosis: an international meta-analysis of individual patient data. Am J Med 2005;118:2-10.

5 Steen VD, Medsger TA. Changes in causes of death in systemic sclerosis, 1972-2002. Ann Rheum Dis 2007:66:940-4.

6 Khanna D, Distler JHW, Sandner P, et al. Emerging strategies for treatment of systemic sclerosis. J Scleroderma Relat Disord 2016;1:186-93.

7 Muangchant C, Pope JE. The significance of interleukin-6 and C-reactive protein in systemic sclerosis: a systematic literature review. Clin Exp Rheumatol 2013;31(2 Suppl 76):122-34.

8 Muangchan C, Pope JE. Interleukin 6 in systemic sclerosis and potential implications for targeted therapy. J Rheumato/ 2012;39:1120-4.

9 Koch AE, Kronfeld-Harrington LB, Szekanecz Z, et al. In situ expression of cytokines and cellular adhesion molecules in the skin of patients with systemic sclerosis. Their role in early and late disease. Pathobiology 1993;61:239-46.

10 Khan K, Xu S, Nihtyanova S, et al. Clinical and pathological significance of interleukin 6 overexpression in systemic sclerosis. Ann Rheum Dis 2012;71:1235-42.

11 De Lauretis A, Sestini P, Pantelidis P, et al. Serum interleukin 6 is predictive of early functional decline and mortality in interstitial lung disease associated with systemic sclerosis. J Rheumato/ 2013:40:435-46.

12 Sato S, Hasegawa M, Takehara K. Serum levels of interleukin- 6 and interleukin-10 correlate with total skin thickness score in patients with systemic sclerosis. J Dermatol Sci 2001;27:140-6.

13 Matsushita T, Hasegawa M, Hamaguchi Y, et al. Longitudinal analysis of serum cytokine concentrations in systemic sclerosis: association of interleukin 12 elevation with spontaneous regression of skin sclerosis. J Rheumatol 2006;33:275-84.

14 Muangchan C, Harding S, Khimdas S, et al. Association of C-reactive protein with high disease activity in systemic sclerosis: results from the Canadian Scleroderma Research Group. Arthritis Care Res 2012;64:1405-14.

15 Genentech Inc. Actemra (tocilizumab) injection for intravenous infusion. South San Francisco, CA: Genentech, Inc, 2017.

16 Shima Y, Kuwahara Y, Murota $H$, et al. The skin of patients with systemic sclerosis softened during the treatment with anti-IL-6 receptor antibody tocilizumab. Rheumatology 2010;49:2408-12.

17 Elhai M, Meunier M, Matucci-Cerinic M, et al. Outcomes of patients with systemic sclerosis-associated polyarthritis and myopathy treated with tocilizumab or abatacept: a EUSTAR observational study. Ann Rheum Dis 2013;72:1217-20.
18 Khanna D, Denton CP, Jahreis A, et al. Safety and efficacy of subcutaneous tocilizumab in adults with systemic sclerosis (faSScinate): a phase 2, randomised, controlled trial. Lancet 2016;387:2630-40.

19 van den Hoogen F, Khanna D, Fransen J, et al. 2013 classification criteria for systemic sclerosis: an American college of rheumatology/European league against rheumatism collaborative initiative. Ann Rheum Dis 2013;72:1747-55.

20 Khanna D, Furst DE, Hays RD, et al. Minimally important difference in diffuse systemic sclerosis: results from the D-penicillamine study. Ann Rheum Dis 2006:65:1325-9.

21 Clopper CJ, Pearson ES. The use of confidence or fiducial limits illustrated in the case ofbinomial. Biometrika 1934;26:404-13.

22 Distler 0, Distler JH. Tocilizumab for systemic sclerosis: implications for future trials. Lancet 2016;387:2580-1.

23 Schiff MH, Kremer JM, Jahreis A, et al. Integrated safety in tocilizumab clinical trials. Arthritis Res Ther 2011;13:R141.

24 Genovese MC, Rubbert-Roth A, Smolen JS, et al. Longterm safety and efficacy of tocilizumab in patients with rheumatoid arthritis: a cumulative analysis of up to 4.6 years of exposure. J Rheumatol 2013:40:768-80.

25 Denton CP, Merkel PA, Furst DE, et al. Recombinant human anti-transforming growth factor beta1 antibody therapy in systemic sclerosis: a multicenter, randomized, placebo-controlled phase I/II trial of CAT-192. Arthritis Rheum 2007;56:323-33.

26 Spiera RF, Gordon JK, Mersten JN, et al. Imatinib mesylate (Gleevec) in the treatment of diffuse cutaneous systemic sclerosis: results of a 1-year, phase lla, single-arm, open-label clinical trial. Ann Rheum Dis 2011;70:1003-9.

27 Foocharoen C, Siriphannon Y, Mahakkanukrauh A, et al. Incidence rate and causes of infection in Thai systemic sclerosis patients. Int J Rheum Dis 2012;15:277-83.

28 Muangchan C, Baron M, Pope J. The 15\% rule in scleroderma: the frequency of severe organ complications in systemic sclerosis. a systematic review. J Rheumatol 2013;40:1545-56

29 Buch MH, Aletaha D, Emery P, et al. Reporting of long-term extension studies: lack of consistency calls for consensus. Ann Rheum Dis 2011;70:886-90.

30 Kowal-Bielecka O, Landewé R, Avouac J, et al. EULAR recommendations for the treatment of systemic sclerosis: a report from the EULAR Scleroderma Trials and Research group (EUSTAR). Ann Rheum Dis 2009;68:620-8.

31 Nagaraja V, Denton CP, Khanna D. Old medications and new targeted therapies in systemic sclerosis. Rheumatology 2015;54:1944-53.

32 Tashkin DP, Elashoff R, Clements PJ, et al. Cyclophosphamide versus placebo in scleroderma lung disease. N Eng/ J Med 2006;354:2655-66.

33 Hoyles RK, Ellis RW, Wellsbury J, et al. A multicenter, prospective, randomized, doubleblind, placebo-controlled trial of corticosteroids and intravenous cyclophosphamide followed by oral azathioprine for the treatment of pulmonary fibrosis in scleroderma. Arthritis Rheum 2006;54:3962-70.

34 Burt RK, Shah SJ, Dill K, et al. Autologous non-myeloablative haemopoietic stemcell transplantation compared with pulse cyclophosphamide once per month for systemic sclerosis (ASSIST): an open-label, randomised phase 2 trial. Lancet 2011;378:498-506.

35 van Laar JM, Farge D, Sont JK, et al. Autologous hematopoietic stem cell transplantation vs intravenous pulse cyclophosphamide in diffuse cutaneous systemic sclerosis: a randomized clinical trial. JAMA 2014;311:2490-8.

36 McSweeney PA, Nash RA, Sullivan KM, et al. High-dose immunosuppressive therapy for severe systemic sclerosis: initial outcomes. Blood 2002;100:1602-10.

37 Pope JE, Bellamy N, Seibold JR, et al. A randomized, controlled trial of methotrexate versus placebo in early diffuse scleroderma. Arthritis Rheum 2001:44:1351-8.

38 van den Hoogen FH, Boerbooms AM, Swaak AJ, et al. Comparison of methotrexate with placebo in the treatment of systemic sclerosis: a 24 week randomized double-blind trial, followed by a 24 week observational trial. Br J Rheumatol 1996:35:364-72

39 Tashkin DP, Roth MD, Clements PJ, et al. Mycophenolate mofetil versus oral cyclophosphamide in scleroderma-related interstitial lung disease (SLS II): a randomised controlled, double-blind, parallel group trial. Lancet Respir Med 2016:4:708-19.

40 Namas R, Tashkin DP, Furst DE, et al. Efficacy of mycophenolate mofetil and oral cyclophosphamide on skin thickness: Post-hoc analyses from the Scleroderma Lung Study I and II. Arthritis Care Res 2017 